\section{The Effects of End-of-the-day Red and Far-red Light on Growth and Flowering of Petunia xhybrida 'Countdown Burgundy' Grown under Photoselective Films}

\author{
Ilias F. Ilias ${ }^{1}$ and Nihal Rajapakse \\ Department of Horticulture, Clemson University, Clemson, SC 29634 \\ Additional index words. plant growth regulation, bedding plants, light quality
}

\begin{abstract}
The objective of this research was to investigate if brief exposure to end-of-the-day (EOD) red (R) or far red (FR) light can overcome the flowering delay of petunia (Petunia xhybrida Vilm.-Andr. 'Countdown Burgundy') grown under FR deficient greenhouse environments with no adverse effects on stem elongation. Plants were grown under clear, $F R$, and $R$ light absorbing greenhouse films (control, $A_{F R}$, and $A_{R}$ films, respectively) and exposed to $R$ or FR light at the end of the photoperiod for 15 minutes. At flowering, main stem of plants grown under the $A_{R}$ film was about $17 \%$ longer and that of $A_{F R}$ film grown plants (without EOD treatment) was about $50 \%$ shorter than control plants. EOD-R light reduced stem elongation of control plants but had no effect on $\mathrm{A}_{\mathrm{FR}}$ or $\mathrm{A}_{\mathrm{R}}$ film-grown plants. EOD-FR light increased stem elongation in plants grown under $A_{R}$ and $A_{F R}$ films but the percentage increase was greater under $A_{\mathrm{FR}}$ film $(7 \%, 19 \%$, and $64 \%$ increase in control, $A_{R}$, and $A_{F R}$ films, respectively). However, plants that received EOD-FR light under $A_{F R}$ film were $25 \%$ shorter than control plants that received no EOD light. $A_{\mathrm{FR}}$ film delayed flowering by 11 days but $A_{R}$ film had no effect. Fifteen-minute exposure to EOD-R or -FR light had no effect on flowering under control and $A_{F R}$ film. Although the exposure to brief EOD-FR partially increased stem elongation, it was not sufficient to accelerate flowering. Treatments to enhance flowering can cause stem elongation. Therefore, care should be taken to avoid improper crop timing, especially with long-day plants.
\end{abstract}

Greenhouse films that remove far red light ( $\mathrm{A}_{\mathrm{FR}}$ films) have been shown to reduce stem elongation of wide range of ornamental and vegetable plants without chemicals (Cerny et al., 2003; Rajapakse et al., 1999). However, variable response to flowering has been observed under $\mathrm{A}_{\mathrm{FR}}$ films depending on the plant species. Cerny et al. (2003) reported that $\mathrm{A}_{\mathrm{FR}}$ films did not affect flowering dayneutral miniature rose (Rosa $\times$ hybrida), while flowering of short-day plants-zinnia (Zinnia elegans Jacq.), cosmos (Cosmos bipinnatus Cav.), and chrysanthemum (Chrysanthemum $\times$ grandiflorum Kitam.) - was slightly delayed (1 to 2 d) under the $A_{F R}$ films. Flowering of long-day (LD) plants - snapdragon (Antirrhinum majus L.) and petunia (Petunia $\times$ hybrida Vilm.-Andr.) - was delayed up to $13 \mathrm{~d}$ by the $\mathrm{A}_{\mathrm{FR}}$ films under weakly inductive photoperiods $\left(<11 \mathrm{~h} \cdot \mathrm{d}^{-1}\right)$ but only a slight delay ( 2 to $\left.3 \mathrm{~d}\right)$ was observed under strongly inductive photoperiods $\left(>13 \mathrm{~h} \cdot \mathrm{d}^{-1}\right)$. The delay in flowering of petunia under weakly inductive photoperiods was attributed to the delay in floral primordia

Received for publication 24 Feb. 2004. Accepted for publication 29 June 2004. This research was supported by the Technological Educational Institute of Thessaloniki, Greece, the Greek Ministry of Education, and The Fred C. Gloeckner Foundation. Technical contribution 5005 of the South Carolina Agricultural Experiment Station.

${ }^{1}$ Present Address: Dept. of Crop Production, Technological Educational Institute, PO Box 14561, Thessaloniki, 541 01, Greece. initiation and overall development of the floral meristem under the FR deficient environment. Kubota et al. (2000) and Runkle and Heins (2002) reported that $A_{F R}$ films reduced the stem elongation of petunia, but did not alter time to flower when grown under inductive photoperiods.

Gibberellins (GAs) and FR light have been shown to affect the transition from vegetative to reproductive stage in certain plants. Applied gibberellins induced flowering of many LD or cold requiring plants under noninductive conditions (Zeevaart, 1983). Supplemental FR light accelerated flowering in Arabidopsis mutants (Bagnall, 1993) and snapdragon [Antirrhinum majus L.] (Cremer et al., 1998).

The role of FR light in GA metabolism has been investigated. Martinez-Garcia and Garcia-Martinez (1992) reported that FR light increased $\mathrm{GA}_{1}$ levels in cowpea seedlings [ $\mathrm{Vi}$ gna unguiculata (L.) Walp. ssp. unguiculata]. Later, Martinez-Garcia et al. (2000) reported that exposure to FR light increased GA levels due to reduced metabolism of $\mathrm{GA}_{1}$. In previous work, Maki et al. (2002) reported that metabolism of precursor GAs $\left(\mathrm{GA}_{12}\right.$ and $\left.\mathrm{GA}_{19}\right)$ in chrysanthemum was slower and metabolism of $\mathrm{GA}_{1}$ may be faster under FR light deficient environments suggesting that reduced active GA levels may be causing the delay in flowering under FR light deficient environments.

Exposure of LD plants to FR light toward the end the photoperiod has been shown to promote flowering (Kadman-Zahavi and Ephart, 1976).
Thomas and Vince-Prue (1997) reported that end of the day FR light exposure accelerated the post inductive flower development in some LDPs. Schneider et al. (1967) reported that after flower initiation, addition of FR light accelerated flower development of Hyoscyamus niger. Runkle and Heins (2003) reported that under FR light deficient environments, flowering of pansy (Viola $\times$ wittrockiana Gams.) was promoted when FR light was added during the 4 hours prior to or after the end of photoperiod but long exposure to FR light promoted stem elongation. The objective of the this work was to determine if brief exposure to R or FR light at the end of natural photoperiod can accelerate the flowering in $\mathrm{A}_{\mathrm{FR}}$ film grown plants without stimulating stem elongation.

\section{Materials and Methods}

Photoselective filters. A clear film and two experimental photoselective greenhouse films with a red $\left(A_{R}\right.$ film $)$ and far red light absorbing dye $\left(\mathrm{A}_{\mathrm{FR}}\right.$ film) were used in all experiments (Mitsui Chemicals Inc., Tokyo, Japan). Six PVC framed growth chambers $(1.2 \times 1.2 \times$ $1.2 \mathrm{~m}$; two for each film) were covered with these films. Photosynthetic photon flux was adjusted for uniformity in all chambers with neutral density filters. Spectral photon distribution was measured on clear days between 12:00 and 14:00 $\mathrm{HR}$ at the beginning and at the end of the experiment with a LI-1800 spectroradiometer fitted with a LI-1800-10 remote cosine sensor (LI-COR, Lincoln, $\mathrm{Neb}$ ). The phytochrome photoequilibrium $\left(\mathrm{P}_{\mathrm{fr}} / \mathrm{P}_{\text {total }}\right)$ estimates of transmitted light for the control, $A_{F R}$, and $A_{R}$ films were 0.71, 0.77, and 0.67, respectively (estimated as described by Sager et al., 1988). The broadband $\mathrm{R} / \mathrm{FR}$ ratios $(\mathrm{R}=$ 600 to $700 \mathrm{~nm}$; FR $=700$ to $800 \mathrm{~nm}$ ) for the control, $\mathrm{A}_{\mathrm{FR}}$, and $\mathrm{A}_{\mathrm{R}}$ films were 1.05, 1.51, and 0.67 , respectively.

Plant material and culture. Experiments were conducted from November 2001 to February 2002 (weakly inductive photoperiod for petunia) and repeated during the same time the following year. 'Countdown Burgundy' petunia seeds were germinated on a greenhouse mist bench set at $22 \pm 2{ }^{\circ} \mathrm{C}$. At the three to four-leaf stage, uniform seedlings were transplanted individually into $0.4-\mathrm{L}$ plastic pots containing a commercial potting mix (Fafard 3-B Mix, Fafard Inc., Anderson, S.C.). Plants were acclimatized for one week in the greenhouse before being subjected to the treatment. All plants were irrigated with $1 \mathrm{~g} \cdot \mathrm{L}^{-1}$ of $20 \mathrm{~N}-4.4 \mathrm{P}-16.7 \mathrm{~K}$ water soluble fertilizer (Peters 20-10-20 Peat-Lite Special, ScottsSierra Horticultural Products Co., Marysville, Ohio) during the experiments. Greenhouse cooling/heating set points were $27 / 20^{\circ} \mathrm{C}$.

After establishment period, 30 plants were transferred to each growth chamber covered with experimental films. Daily light integral (DLI) inside the photoselective chambers were recorded with a LI-1000 datalogger fitted with LI-190SB quantum sensors (programmed to collect readings every $5 \mathrm{~min}$ ) during each set of experiments. The photoperiod was determined based on the U.S. Naval Observatory sunrise 
and sunset table for Greenville, S.C. Hourly air temperature inside chambers was monitored using type $\mathrm{T}$ thermocouples placed above the plant canopy and connected to an Omnidata EasyLogger (EL 824, Omnidata International Inc., Logan, Utah). Plants received an average natural photoperiod of $10.5 \mathrm{~h}$ and DLI of 7.4 $\pm 3(\mathrm{SD}) \mathrm{mol} \cdot \mathrm{m}^{-2} \cdot \mathrm{d}^{-1}$ during the experiment. Average day and night air temperatures inside chambers were $23 \pm 2{ }^{\circ} \mathrm{C}$ and $19 \pm 2{ }^{\circ} \mathrm{C}$, respectively. Average air temperatures and DLI inside the chambers were not significantly different between two experimental runs.

At the end of the photoperiod, 10 plants from each chamber were exposed to $\mathrm{R}$ light [2.1 W. $\mathrm{m}^{-2}$ in 600 to $700 \mathrm{~nm}$ obtained from six 40-W cool-white fluorescent bulbs filtered through a Roscolux \#19 acetate filter (Rosco, Port Chester, N.Y.); estimated $\mathrm{P}_{\mathrm{fr}} / \mathrm{P}_{\text {total }}$ of 0.85$]$ or FR light $\left[12.0 \mathrm{~W} \cdot \mathrm{m}^{-2}\right.$ in 700 to $800 \mathrm{~nm}$ obtained from two internal-reflector incandescent bulbs filtered through polyacrylic sheet of cast acrylic \#2711 dark red filter (Rohm and Haas, Bristol, Pa.); estimated $\mathrm{P}_{\mathrm{fr}} / \mathrm{P}_{\text {total }}$ of 0.11] for $15 \mathrm{~min}$ in specially designed light treatment boxes to prevent possible contamination with outside light. Following EOD light treatment, plants were returned to the photoselective film chambers. EOD light treatment was terminated when flower buds were visible.

Experimental design and data analysis. Six photoselective film chambers (two replicates for each film treatment) were randomly placed inside the greenhouse to receive natural radiation. EOD light treatments were randomized within each film in a $2 \times 3$ factorial split-plot arrangement with film as the main plot and EOD-treatment as the split plot. Ten single plants were used in each treatment combination and replication. Main stem length (measured weekly from medium surface to apex), days

Table 1. The effect of end-of day (EOD) R or FR light on main stem height, days to flower (DF), number of open flowers (NF), and number of flower buds (NB) of petunia plants grown inside photoselective films. Each number is the mean of 20 plants.

\begin{tabular}{|c|c|c|c|c|c|}
\hline$\overline{\text { Film }^{2}}$ & EOD & $\mathrm{Ht}^{\mathrm{y}}(\mathrm{cm})$ & $\mathrm{DF}$ & $\mathrm{NF}^{\mathrm{y}}$ & $\mathrm{NB}^{\mathrm{y}}$ \\
\hline \multirow[t]{3}{*}{ Control } & None $(\mathrm{N})$ & 12.8 & 59 & 4.8 & 4.1 \\
\hline & $\mathrm{R}$ & 10.2 & 62 & 3.9 & 3.7 \\
\hline & FR & 13.7 & 57 & 3.4 & 3.5 \\
\hline \multirow[t]{3}{*}{$A_{R}$} & None $(\mathrm{N})$ & 14.9 & 60 & 3.9 & 4.6 \\
\hline & $\mathrm{R}$ & 13.4 & 63 & 4.0 & 5.6 \\
\hline & FR & 17.8 & 52 & 4.3 & 6.0 \\
\hline \multirow{3}{*}{$A_{F R}$} & None $(\mathrm{N})$ & 5.8 & 70 & 2.8 & 2.3 \\
\hline & $\mathrm{R}$ & 4.8 & 68 & 3.1 & 3.0 \\
\hline & FR & 9.5 & 69 & 2.2 & 2.8 \\
\hline \multicolumn{6}{|l|}{ Anova $^{x}$} \\
\hline Film & & $*$ & $* * *$ & $*$ & $*$ \\
\hline EOD & & ** & $* * *$ & NS & NS \\
\hline Film $\times$ EOD & & NS & $* *$ & NS & NS \\
\hline \multicolumn{6}{|l|}{ Contrasts } \\
\hline Control $\mathrm{N}$ vs. $\mathrm{A}_{\mathrm{p}} \mathrm{N}$ & & $* *$ & NS & NS & NS \\
\hline Control N vs. $A_{\mathrm{FR}}^{\mathrm{K}} \mathrm{N}$ & & $* * *$ & $* * *$ & ** & $* *$ \\
\hline Control N vs. $A_{\mathrm{RP}}^{\mathrm{RR}} \mathrm{R}$ & & $* * *$ & $* * *$ & $*$ & NS \\
\hline Control $N$ vs. $A_{\mathrm{FR}}^{\mathrm{FR}}$ FR & & $* * *$ & $* * *$ & $* * *$ & NS \\
\hline$A_{R}: N$ vs. $R$ & & NS & NS & NS & NS \\
\hline $\mathrm{N}^{\mathrm{R}}$ vs. FR & & $* * *$ & $* * *$ & NS & * \\
\hline$A_{\mathrm{FR}}: \mathrm{N}$ vs. $\mathrm{R}$ & & NS & NS & NS & NS \\
\hline $\mathrm{N}$ vs. FR & & $* * *$ & NS & NS & NS \\
\hline Control: $\mathrm{N}$ vs. $\mathrm{R}$ & & ** & NS & NS & NS \\
\hline N vs. FR & & NS & NS & NS & NS \\
\hline
\end{tabular}

${ }^{2}$ Control, $A_{R}$, and $A_{F R}$ are clear, red, and far red light absorbing films, respectively.

${ }^{y}$ Measured at the end of the experiment (when all plants had at least one open flower).

NS,,$* * * * * * *$ Nonsignificant or significant at $P=0.05,0.01$, or 0.001 respectively. light deficient environment but had no effect under control filter (Rajapakse et al., 1993). Exposure to EOD-R light reduced stem elongation of chrysanthemum plants grown under control filter but had no effect under FR light deficient filter

$A_{\mathrm{FR}}$ film delayed flowering of petunia by $11 \mathrm{~d}$ while $A_{R}$ film had no effect (Table 1). $A_{F R}$ film grown plants had less number of flowers than control or $A_{R}$ film grown plants at the time of harvest. However, this could be due to the slower growth under $\mathrm{A}_{\mathrm{FR}}$ film. Petunia 'Countdown Burgundy' is a quantitative LD plant in which flowering is hastened under long photoperiod (Adams et al., 1998). Similar to present results, Cerny et al. (2003) reported that $A_{\mathrm{FR}}$ films delayed flowering of petunia by $13 \mathrm{~d}$ during weakly inductive photoperiods $\left(<11 \mathrm{~h} \cdot \mathrm{d}^{-1}\right)$ but the delay reduced as the photoperiod increased. During strongly inductive photoperiods $\left(>13 \mathrm{~h} \cdot \mathrm{d}^{-1}\right)$ only $2-$ to $3-\mathrm{d}$ delay in flowering occurred in petunia, snapdragon and pansy under $\mathrm{A}_{\mathrm{FR}}$ films (Cerny et al., 2003; Runkle and Heins, 2002).

Fifteen-minute exposure to EOD-R or -FR light had no effect on flowering under control and $\mathrm{A}_{\mathrm{FR}}$ film but slightly accelerated flowering under $A_{R}$ film. End of the day light treatments did not affect number of flowers. Runkle and Heins (2003) reported that under FR light deficient environments, addition of FR light during the entire photoperiod or $4 \mathrm{~h}$ before or after the end of photoperiod promoted flowering of pansy. They also reported that under the FR light deficient environments, 2 to 4 hof night interruption (NI) with low to moderate ( 0.6 to 1.3) R:FR light sources promoted flowering of pansy but a 4-h NI with high R:FR light did not promote flowering. However, long exposures to FR light, either at end of the day or as NI, promoted stem elongation nullifying the benefits of height control.

Our results confirmed that $\mathrm{A}_{\mathrm{FR}}$ film delayed anthesis of petunia when grown during weakly inductive photoperiods. Although the exposure to brief EOD-FR partially increased stem elongation, it was not sufficient to accelerate flowering. EOD-R light did not affect stem elongation but was not effective in flower promotion. Long exposure to EOD-FR or night break with FR rich light can enhance flowering but it also stimulates stem elongation nullifying the benefit of height reduction by $A_{\mathrm{FR}}$ film. We have shown that $\mathrm{GA}_{4}$ promoted flowering of petunia under $\mathrm{A}_{\mathrm{FR}}$ films but stimulated stem elongation (Cerny et al., 2005). The C-16,17-dihydro $\mathrm{GA}_{5}$, a $\mathrm{GA}_{5}$ derivative that has been shown to reduce stem elongation and promote flowering of monocots such as barley (Hordeum vulgare L.) and some dicot species (Ben-Tal and Belausov, 2000; Evans et al., 1994), failed to promote flowering of petunia under $\mathrm{A}_{\mathrm{FR}}$ films when used alone and failed to stop stem elongation when used in combination with $\mathrm{GA}_{4}$. Since treatments to enhance flowering can cause stem elongation care should be taken to avoid improper crop timing, especially with long-day plants, if/when greenhouse light manipulation becomes a commercial reality for nonchemical height control of ornamental crops. 


\section{Literature Cited}

Adams, S.R., P. Hadley, and S. Pearson. 1998. The effects of temperature, photoperiod, and photosynthetic photon flux on the time to flowering of petunia 'Express Blush Pink'. J. Amer. Soc. Hort. Sci. 123:577-580.

Bagnall, D.J. 1993. Light quality and vernalization interact in controlling late flowering in Arabidopsis ecotypes and mutants. Ann. Bot. 71:75-83.

Ben-Tal, Y. and O.E. Belausov. 2000. Under what circumstances can gibberellins substitute the environmental flowering induction. Proc. Plant Growth Reg. Soc. Amer. 27:311.

Cerny, T.A., J. Faust, D. Layne, and N.C. Rajapakse. 2003. Flower development of photoperiod sensitive species under modified light environments. J. Amer. Soc. Hort. Sci. 128:486-491.

Cerny, T.A., J. Faust, and N.C. Rajapakse. 2005. Role of gibberellin $\mathrm{A}_{4}$ and gibberellin biosynthesis inhibitors on flowering and stem elongation of petunia under modified light environments. HortScience 40(1):134-137.

Cremer, F., A. Havelange, H. Saedler, and P. Huijser. 1998. Environmental control of flowering time in Antirrhinum majus. Physiol. Plant. 104:345-350.

Evans, L.T., R.W. King, L.N. Mander, R.P. Pharis, and K.A. Duncan. 1994. The differential effects of C-16,17-dihydro gibberellins and related compounds on stem elongation and flowering in
Lolium temulentum. Planta 193:107-114.

Kadman-Zahavi, A. and E. Ephrat. 1976. Development of plants in filtered sunlight. II. Effects of spectral composition, light intensity, day length, red and far-red irradiation on long- and short- day grasses. Israel J. Bot. 25:11-23.

Kubota, S., T. Yamato, T. Hisamatsu, S. Esaki, R. Oi, M.S. Roh, and M. Koshioka. 2000. Effects of red- and far-red-rich spectral treatments and diurnal temperature alternation of the growth and development of petunia. J. Jpn. Soc. Hort. Sci. 69:403-409.

Maki, S.L., S. Rajapakse, R.E. Ballard, and N. Rajapakse. 2002. Role of gibberellins in chrysanthemum growth under far-red light-deficient greenhouse environments. J. Amer. Soc. Hort. Sci. 127:639-643.

Martinez-Garcia, J.R. and J.L. Garcia-Martinez 1992. Interaction of gibberellins and phytochrome in the control of cowpea epicotyl elongation. Physiol. Plant. 86:236-244.

Martinez-Garcia, J.F., C.M. Santes, and J.L. GarciaMartinez. 2000. The end-of-day far-red irradiation increases GA content in cowpea (Vigna sinensis) epicotyl by reducing its inactivation. Physiol. Plant. 108:526-434.

Mortensen, L.M. and E. Stromme. 1987. Effects of light quality on some greenhouse crops. Scientia Hort. 33:27-36.

Rajapakse, N.C., M.J. McMahon, and J.W. Kelly. 1993. End of day far-red light reverses the height reduction of chrysanthemum caused by copper sulfate spectral filters. Scientia Hort. 53:249-259.

Rajapakse, N.C., R.E. Young, M.J. McMahon, and R. Oi. 1999. Plant height control by photoselective filters: current status and future prospects. HortTechnology 9:618-624.

Runkle, E.S. and R.D. Heins. 2002. Stem extension and subsequent flowering of seedlings grown under a film creating a far-red deficient environment. Scientia Hort. 96:257-265.

Runkle, E.S. and R.D. Heins. 2003. Photocontrol of flowering and extension growth in the long-day plant pansy. J. Amer. Soc. Hort. Sci. 128:479-485.

Sager, J.C., W.O. Smith, J.C. Edwards, and K.L. Cyr. 1988. Photosynthetic efficiency and phytochrome photoequilibrium determination using spectral data. Trans. Amer. Soc. Agr. Eng. 31:1882-1887.

Schneider, M.J., H.A. Borthwick, and S.B. Hendricks. 1967. Effects of radiation on flowering of Hyoscyamus niger. Amer. J. Bot. 54:1241-1249.

Thomas, B. and D. Vince-Prue. 1997. Photoperiodism in plants. Academic Press, San Diego, Calif.

Zeevaart, J.A.D. 1983. Gibberellins and flowering, p. 333-374. In: A. Crozier (ed.). The biochemistry and physiology of gibberellins. vol 2. Prager, New York, 